\title{
The Hemodynamic Effects of Antenatal Indomethacin and a $\beta$-Sympathomimetic Agent on the Fetus and the Newborn: A Randomized Study ${ }^{1}$
}

\author{
MARIANNE ERONEN \\ Children's Hospital, Division of Pediatric Cardiology, University of Helsinki, Helsinki, Finland
}

\begin{abstract}
To study the effect of antenatal indomethacin or nylidrin hydrochloride treatment on the fetal and neonatal ductus arteriosus and tricuspid valve function, 84 pregnant women with threatened premature birth between 22.9 and 34.0 wk gestation and 94 of their offspring born at 24.7 to 41.6 wk of gestation were studied by Doppler echocardiography. Forty-six women were treated with indomethacin and 38 with nylidrin. Both peak systolic and peak diastolic velocities in the ductus increased after administration of indomethacin and exceeded the corresponding velocities in the fetuses of the nylidrin group ( $p=$ 0.0001 ). Ductal constriction occurred in 42 of 49 fetuses treated with indomethacin $(86 \%)$. Tricuspid valve regurgitation (TR) was evident in 11 of 49 fetuses treated with indomethacin $(22 \%)$. The mean gestational age of the fetuses with TR $(30.0 \mathrm{wk})$ tended to be higher than those without TR (28.3 wk, $p=0.056$ ). In the nylidrin group, no fetus had ductal constriction or TR. A significant increase in peak systolic velocity $(r=0.54, p=0.0001)$ and in peak diastolic velocity $(r=0.46, p=0.0001)$ in the ductus with advancing gestational age was demonstrated in the indomethacin group; however, in the nylidrin group, there was a less remarkable increase in peak systolic velocity $(r=$ $0.35, p=0.04)$ and no increase in peak diastolic velocity $(r=0.02, p=0.93)$. In infants born at or before $35 \mathrm{wk}$ gestation, incidences of both spontaneous closure and indomethacin-induced closure of ductus were similar in both study groups $(p>0.1)$. Ductal reopening tended to occur more frequently after indomethacin $(17 \%)$ than after nylidrin $(0 \%)$ administration $(p=0.15)$. These findings indicate that: 1 ) the fetal ductus becomes more reactive to indomethacin with increasing gestational age; 2) TR tends to occur in fetuses with advanced gestational age; and 3) prenatal exposure of indomethacin does not decrease the need for patent ductus arteriosus treatment in premature infants. (Pediatr Res 33: 615-619, 1993)
\end{abstract}

\section{Abbreviations}

PDA, patent ductus arteriosus

PDV, peak diastolic velocity

PSV, peak systolic velocity

RDS, respiratory distress syndrome

$\mathrm{TR}$, tricuspid valve regurgitation

Received September 10, 1992; accepted January 18, 1993.

Correspondence and reprint requests: Marianne Eronen, M.D., The Children's Hospital, Division of Pediatric Cardiology, University of Helsinki, Stenbackinkatu 11, 00290, Helsinki, Finland.

Supported by grants from the Foundation for Pediatric Research, Aarne Koskelo Foundation, and Research and Science Foundation of Farmos.

${ }^{1}$ Presented in part at the American College of Cardiology 42nd Annual Scientific Session in Anaheim, CA, on March 14-18, 1993.
The common therapy for inhibiting preterm labor process is administration of $\beta$-sympathomimetic agents. However, these drugs have no beneficial effect on perinatal mortality or on the frequency of prolongation of pregnancy to term $(1,2)$. In addition, they have several potential cardiovascular side effects. In pregnant women, cases of myocardial ischemia, supraventricular tachycardia, and pulmonary edema have been reported $(2,3)$. Cases of myocardial toxicity have been reported in infants of mothers treated with a $\beta$-sympathomimetic agent $(4,5)$.

Indomethacin has been recently used as a tocolytic drug. It readily crosses to the placenta (6) and may cause a transient vasoconstriction of the fetal ductus arteriosus (7). Postnatally, indomethacin is the drug of choice in the treatment of persistent ductus arteriosus (8).

We have demonstrated that fetal ductus becomes more reactive to indomethacin with increasing gestational age (9). The primary objective of this study was to further evaluate whether the degree of ductal constriction and especially the occurrence of TR depend on the length of gestation. The secondary objective was to determine whether prenatal exposure to indomethacin decreases the requirements of indomethacin or surgery for treatment of PDA in premature infants.

\section{PATIENTS AND METHODS}

A total of 84 pregnant women with threatened premature birth between 22.9 and 34.0 wk gestation were enrolled in the study at the University Central Hospital, Helsinki, Finland (Table 1). None of the women had pregnancy-induced hypertension. Indomethacin treatment was given to 46 and nylidrin treatment to 38 women for tocolysis. Their 94 offspring, born at 24.7 to 41.6 wk of gestation, were included in the study. The study protocol was approved by the Hospital Ethics Committee.

Of those 84 pregnant women, 48 were randomly and blindly allocated (a sealed envelope) to receive either indomethacin $(n=24)$ or nylidrin hydrochloride $(n=24)$. The treatments were identical in appearance, so that each patient received an i.v. infusion containing either nylidrin or placebo and oral capsules containing either indomethacin or placebo (10). In addition, 36 women were randomized according to the date of birth to receive either indomethacin (odd year number; $n=22$ ) or nylidrin (even year number; $n=14$ ). The dosage of indomethacin (Orion Pharmaceutica, Espoo, Finland) consisted of an initial rectal suppository $(100 \mathrm{mg}$ ) followed by eight oral capsules $(50 \mathrm{mg})$ at 8-h intervals. Nylidrin (Orion Pharmaceutica) was infused i.v. in physiologic saline with an initial dose of $50 \mu \mathrm{g} / \mathrm{min}$; this was increased within $30 \mathrm{~min}$ to the maintenance dose of 100 to 150 $\mu \mathrm{g} / \mathrm{min}$. Both treatments were administered until cessation of 
Table 1. Clinical characteristics of study population*

\begin{tabular}{lcc} 
& $\begin{array}{c}\text { Indomethacin } \\
\text { group }\end{array}$ & $\begin{array}{c}\text { Nylidrin } \\
\text { group }\end{array}$ \\
\hline No. of women & 46 & 38 \\
No. of fetuses & 53 & 41 \\
$\quad$ Singles & 40 & 36 \\
$\quad$ Twins or triplets & 13 & 5 \\
Maternal age (y) & $29.3 \pm 5.8$ & $30.1 \pm 5.1$ \\
Gestational age at study entry (wk) & $28.8 \pm 2.9$ & $29.5 \pm 2.7$ \\
Gestational age at birth (wk) & $35.9 \pm 4.7$ & $34.3 \pm 4.1 \dagger$ \\
Birth weight (g) & $2682 \pm 1064$ & $2378 \pm 828$ \\
Sex (M/F) & $30 / 23$ & $24 / 17$ \\
\hline
\end{tabular}

* All values are mean $\pm \mathrm{SD}$.

† Significant difference between the study groups; $p<0.05$.

contractions or for a maximum of $3 \mathrm{~d}$. The indomethacin treatment, if needed, was repeated after $7 \mathrm{~d}$.

Two-dimensionally guided, pulsed, and continuous-wave Doppler equipment (Advanced Technology Laboratories 600 MK or Toshiba SSH 65 A color Doppler system; 3.75 and 5 $\mathrm{MHz}$, respectively) was used for examination of the fetal and neonatal heart. The fetal heart was studied once before the therapy, one or two times during the therapy (12 and 24 to $36 \mathrm{~h}$ after the start), and one or two times after discontinuation of the therapy ( 24 or $72 \mathrm{~h}$ later). The ultrasound examinations were repeated when indomethacin was used. The ductal arch was obtained either in longitudinal or in short-axis view, depending on the orientation of the fetus. The aortic arch was differentiated from the ductus arteriosus by identification of the aortic arch vessels. The Doppler beam was positioned at the junction of the ductus and descending aorta until $\mathrm{V}_{\max }$ was attained (11). The Doppler tracings were accepted when the angle between the Doppler beam and the direction of flow was $15^{\circ}$ or less. Ductal PSV and PDV were measured. An average of three beats was used to establish each value. Serial studies demonstrated the change in ductal flow velocity during treatment, but only the examination with the highest flow velocity was used for analysis (11).

Evidence of TR was sought from the four-chamber view in each examination. Valve regurgitation was visualized as a holosystolic regurgitant flow by pulsed, continuous-wave, or color Doppler ultrasonography. Fetal heart rate was registered. All studies were recorded on videotape for later playback and analysis.

The patency of ductus arteriosus in the neonates was determined by Doppler ultrasound at $6,18,30$, and $72 \mathrm{~h}$ after birth and thereafter daily until the ductus was closed. In case of a suspicion of ductal reopening, the scan was repeated. To assess the direction of ductal shunting, the pulmonary artery, ductus arteriosus, and aorta were visualized in a high left sternal view. In open ductus, a unidirectional or bidirectional shunting was demonstrated (12). Hemodynamically significant ductus arteriosus was defined as left to right shunt in the ductus, associated with clinical signs of PDA (hyperdynamic precordium, collapsing pulses, or central pulmonary edema on chest x-ray). The hemodynamically significant PDA was treated with indomethacin, provided that no contraindications were present. The decision to treat the PDA was made by medical staff not involved with the study protocol. Indomethacin was administered i.v. $(0.2 \mathrm{mg} / \mathrm{kg} /$ dose) and it was repeated twice $(0.1 \mathrm{mg} / \mathrm{kg} /$ dose $), 12$ and $24 \mathrm{~h}$ later. After the indomethacin treatment, the ductal patency or closure was confirmed by ultrasound. In case of patency, indomethacin treatment was repeated. After two courses of indomethacin treatment, infants with PDA and congestive cardiac failure underwent surgical ligation.

Pulmonary hypertension was defined as bidirectional ductal shunting or as a suprasystemic pulmonary artery pressure, calculated from tricuspid regurgitant Doppler velocity (in $\mathrm{mm} \mathrm{Hg}$ ), plus assumed right atrial pressure (13).
Data analysis. The statistical significance between the clinical variables of the two study groups was examined by unpaired $t$ test, Mann-Whitney $\mathrm{U}$ test, and $\chi^{2}$ analysis. The results are expressed as means \pm SD. To compare the ductal flow velocities between the two tocolytic groups, an unpaired $t$ test was used. The longitudinal changes in ductal velocities were evaluated by the analysis of variance (repeated measurements). The significance of the relationship between the ductal flow velocity and the gestational age during tocolysis was evaluated by regression analysis (Pearson's correlation coefficient). Patency or spontaneous closure of PDA and the frequencies of treatment of PDA (indomethacin, ligation, or both) for the study groups were compared by $\chi^{2}$ analysis. The ages at spontaneous closure, ages at first dose of indomethacin, or time interval between first dose and closure of PDA were compared between the two study groups by Mann-Whitney $U$ test. A $p$ value of $<0.05$ was considered significant.

\section{RESULTS}

Characteristics of pregnancies, fetuses, and neonates. The pregnant women receiving either indomethacin or nylidrin were comparable with each other on the basis of clinical variables listed in the Table 1. The length of the tocolytic treatment was an average $47 \mathrm{~h}$ (range 12 to $72 \mathrm{~h}$ ). Altogether, seven women needed more than one course of indomethacin treatment. Four women had two courses, two had three courses, and one had five courses of indomethacin. Four of the seven women had multiple pregnancies. Gestational age at birth was significantly higher in indomethacin-treated infants than in nylidrin-treated infants $(p=0.03$ ). There were three neonatal deaths (one girl and two boys); two in the indomethacin and one in the nylidrin group. All who died were born between 24 and 27 wk and weighed between 680 and $1005 \mathrm{~g}$. The deaths were due to severe RDS (three) accompanied by pulmonary hypertension (one), streptococcus group B sepsis (one), and grade 3 to 4 intraventricular hemorrhage (one).

Ductal flow velocities in fetuses. Of the 94 fetuses, 88 were studied using echocardiography. Measurements during tocolytic treatment failed in five fetuses because of maternal discomfort. Altogether, 83 fetuses (49 in the indomethacin group and 34 in the nylidrin group) could be measured reliably. Among them, 103 observations of peak flow velocity values during tocolytic

Table 2. Flow velocity values in fetal ductus arteriosus during 22.9 to 34.0 wk gestation in indomethacin and nylidrin groups

$\frac{\text { Indomethacin }}{\text { Mean SD Range }} \frac{\text { Nylidrin }}{\text { Mean SD Range }}$

\begin{tabular}{|c|c|c|c|c|c|c|}
\hline \multicolumn{7}{|l|}{ Values before treatment } \\
\hline No. of measurements & 19 & & & 13 & & \\
\hline Heart rate/min & 142 & 12 & $115-175$ & 145 & 11 & $120-175$ \\
\hline PSV $(c$ & 97.2 & 17.5 & $73-132$ & 97.3 & 18.4 & 126 \\
\hline PDV $(c$ & 20.8 & 5.4 & $12-32$ & 21.6 & 4.4 & $16-31$ \\
\hline \multicolumn{7}{|l|}{ Values during treatment } \\
\hline No. & 69 & & & 34 & & \\
\hline Hear & 145 & 12 & $120-180$ & 155 & 12 & 130 \\
\hline PS & 162.5 & 35.8 & $88-$ & 108.5 & 17.5 & $80-145 t$ \\
\hline PDV & 54.8 & 25.2 & $18-145$ & 21.9 & 5.5 & $12-35 \dagger$ \\
\hline \multicolumn{7}{|l|}{ Values after treatment } \\
\hline No. & 50 & & & 16 & & \\
\hline Heart & 141 & 12 & $120-175$ & 143 & & 120 \\
\hline PSV & 110.7 & 20.7 & $80-168$ & 102.4 & 11.9 & $83-135$ \\
\hline $\operatorname{PDV}(\mathrm{cm} / \mathrm{s})$ & 23.7 & 7.3 & $14-45$ & 19.3 & 5.2 & $14-31 \ddagger$ \\
\hline
\end{tabular}

* Significant difference in the heart rates between the study groups; $p=0.0003$.

$\uparrow$ Significant differences in PSV and in PDV between the study groups; $p=0.0001$.

$\ddagger$ Significant difference in PDV between the study groups; $p<0.05$. 
therapy were recorded: 69 during indomethacin treatment and 34 during nylidrin treatment.

The intrauterine ductal flow velocity values and heart rates before, during, and after treatments are shown in Table 2. The PSV and PDV were significantly higher during indomethacin treatment than during nylidrin treatment $(p=0.0001)$. Altogether, 42 fetuses $(86 \%)$ in the indomethacin group had ductal constriction (PSV of more than $140 \mathrm{~cm} / \mathrm{s}$ and PDV of more than $35 \mathrm{~cm} / \mathrm{s}$ ) when studied at a mean age of $29.2 \mathrm{wk}$ (range, 24.0 to $34.0 \mathrm{wk})$. The mean PSV in these fetuses was $174 \mathrm{~cm} / \mathrm{s}$ (range, 140 to $255 \mathrm{~cm} / \mathrm{s}$ ), and mean PDV was $63 \mathrm{~cm} / \mathrm{s}$ (range, 36 to $145 \mathrm{~cm} / \mathrm{s}$ ). Seven fetuses (14\%) in the indomethacin group had no evidence of ductal constriction. The mean gestational age of these fetuses was $25.9 \mathrm{wk}$ (range, 24.3 to $28.6 \mathrm{wk}$ ); this was significantly less $(p=0.002)$ than the gestation of the fetuses with ductal constriction. The mean PSV of these fetuses was 123 $\mathrm{cm} / \mathrm{s}$ (range, 103 to $136 \mathrm{~cm} / \mathrm{s} ; p=0.0001$ ), and mean PDV was $31 \mathrm{~cm} / \mathrm{s}$ (range, 18 to $41 \mathrm{~cm} / \mathrm{s} ; p=0.002$ ).

In the nylidrin group, no fetus had ductal constriction. Three fetuses ( 29 to 33 wk gestation) had a clearly elevated PSV in the ductus during treatment $(142$ to $145 \mathrm{~cm} / \mathrm{s})$. No fetus in this group had a PDV of more than $35 \mathrm{~cm} / \mathrm{s}$ (range, 12 to $35 \mathrm{~cm} / \mathrm{s}$ ). The mean heart rate during nylidrin administration was significantly higher than during indomethacin administration (155 beats $/ \mathrm{min}$ versus 145 beats $/ \mathrm{min} ; p=0.0003$ ).

Ductal flow velocities increased significantly in both groups during tocolytic treatment. In the indomethacin group, the change was significant in both PSV (mean, $56 \mathrm{~cm} / \mathrm{s}$; range, 8 to $131 \mathrm{~cm} / \mathrm{s}$ ) and PDV (mean, $33 \mathrm{~cm} / \mathrm{s}$; range, 1 to $94 \mathrm{~cm} / \mathrm{s}$ ) ( $p=0.0001, n=19$ ); whereas, in the nylidrin group, only the PSV increased (mean $16 \mathrm{~cm} / \mathrm{s}$; range, 0 to $40 \mathrm{~cm} / \mathrm{s})(p=0.002$, $n=13$ ).

The relationship between ductal flow velocities and gestational age in both study groups is presented in Figures 1 and 2 . In the indomethacin group, both PSV and PDV correlated with gestational age $(r=0.54, p=0.0001$, and $r=0.46, p=0.0001$, respectively; Fig. 1). A less marked relationship was seen in PSV in the nylidrin group ( $r=0.35, p=0.04$; Fig. 2$)$. There was no detectable change in the PDV as a function of the gestational age in the nylidrin group ( $r=0.02, p=0.93$; Fig. 2$)$.

$T R$. Eleven fetuses in the indomethacin group (22\%) had TR. All these fetuses had ductal constriction. Gestational age and

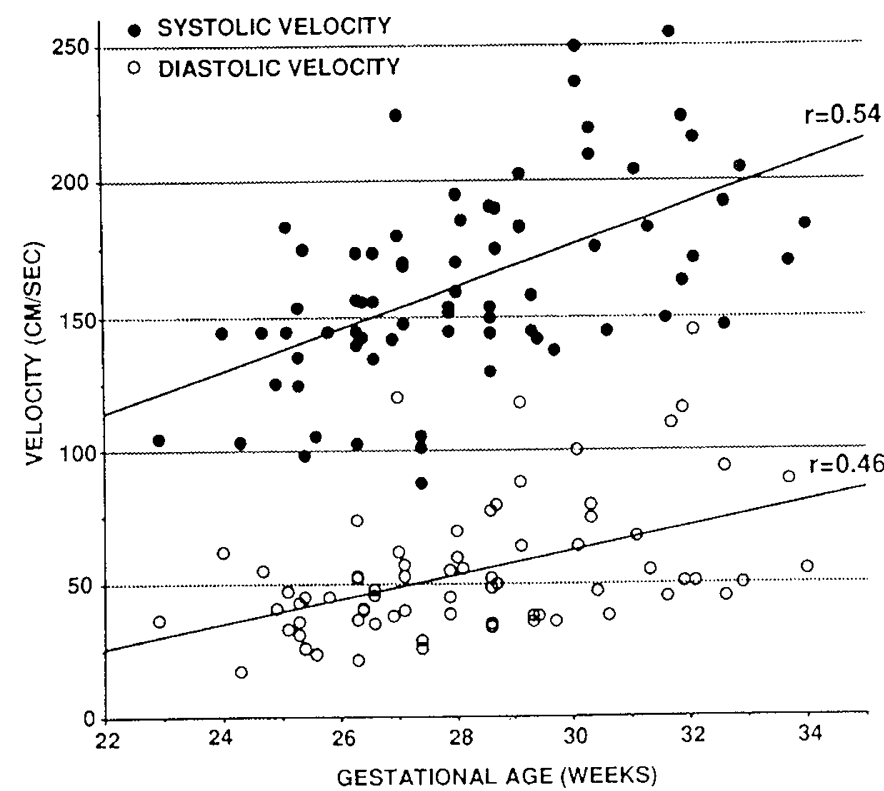

Fig. 1. PSV and PDV $(\mathrm{cm} / \mathrm{s})$ in the fetal ductus during maternal indomethacin treatment. A significant increase in PSV $(r=0.54, p=$ $0.0001)$ and $\operatorname{PDV}(r=0.46, p=0.0001)$ with advancing gestational age was demonstrated in 69 measurements.

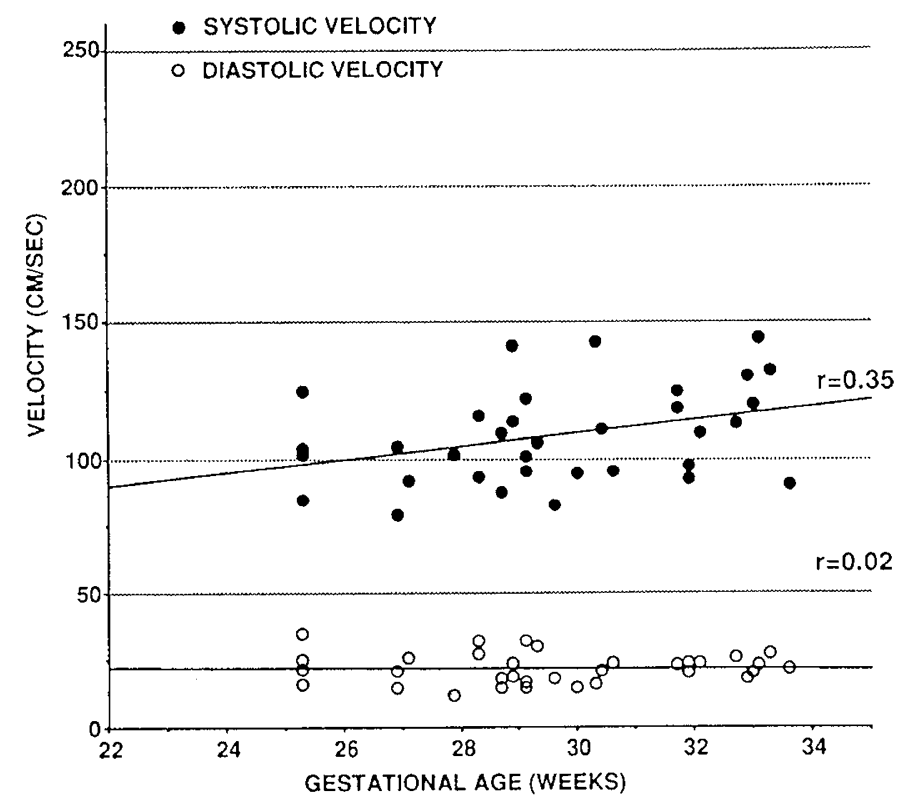

Fig. 2. PSV and $\operatorname{PDV}(\mathrm{cm} / \mathrm{s})$ in the fetal ductus during maternal nylidrin treatment. A moderate increase in PSV $(r=0.35, p=0.04)$ and no increase in PDV $(r=0.02, p=0.93)$ with advancing gestational age was demonstrated in 34 measurements.

Table 3. Tricuspid valve regurgitation in indomethacin-treated fetuses*

\begin{tabular}{lccc}
\hline & $\begin{array}{c}\text { Fetuses } \\
\text { without TR }\end{array}$ & $\begin{array}{c}\text { Fetuses } \\
\text { with TR }\end{array}$ & $p$ \\
\hline No. of fetuses & 38 & 11 & \\
Singles & 28 & 8 & \\
Twins or triplets & 10 & 3 & \\
Gestational age (wk) & $28.3 \pm 2.5$ & $30.0 \pm 2.9$ & 0.056 \\
Range & $24.0-33.6$ & $25.7-34.0$ & \\
Ductal flow velocities & & & \\
PSV & $161.7 \pm 30.8$ & $181.1 \pm 29.6$ & 0.055 \\
Range & $103-255$ & $140-237$ & \\
PDV & $54.7 \pm 25.5$ & $69.0 \pm 25.6$ & 0.071 \\
Range & $18-135$ & $36-126$ & \\
\hline
\end{tabular}

$*$ All values are mean \pm SD and range; $n=49$.

ductal PSV and PDV tended to be higher in the fetuses with TR than in fetuses without TR (Table 3). TR resolved within $24 \mathrm{~h}$ after treatment in nine fetuses (mean gestational age, $29.3 \pm 2.8$ wk) and within $72 \mathrm{~h}$ in two (32.6 and 34.0 wk gestation; $p=$ $0.06)$. In the nylidrin group, at no time in any fetus was there evidence of TR.

There were three twins with TR. The mothers received indomethacin at 26.3,26.4, and 29.3 wk gestation. The mean PSV in these fetuses was $162.5 \mathrm{~cm} / \mathrm{s}$ (range, 147 to $184 \mathrm{~cm} / \mathrm{s}$ ) and mean PDV $46 \mathrm{~cm} / \mathrm{s}$ (range, 36 to $55 \mathrm{~cm} / \mathrm{s}$ ). One twin (gestation $27.0 \mathrm{wk}$, birth weight $1005 \mathrm{~g}$ ) who was delivered during indomethacin treatment died of severe RDS and pulmonary hypertension at the age of $18 \mathrm{~h}$. Autopsy revealed closed ductus.

Closure of ductus arteriosus in neonates. All 94 newborn infants were included in the outcome analysis. The frequencies of the spontaneous closure and of treatment of PDA in the two study groups are shown in Table 4 . In the neonates born after 35 wk gestation $(n=55)$, there were no significant differences in gestational age $(p=0.08)$ or birth weight $(p=0.26)$ between the indomethacin or nylidrin groups. In addition, the age of the infants at the time of spontaneous closure was not significantly different between the groups $(p=0.54)$. None of these neonates had any treatment for the PDA. 
Table 4. Spontaneous closure of ductus arteriosus and treatment of PDA in neonates born after 35 wk gestation and in neonates born at or before 35 wk gestation*

\begin{tabular}{|c|c|c|}
\hline & $\begin{array}{l}\text { Indomethacin } \\
\text { group }\end{array}$ & $\begin{array}{l}\text { Nylidrin } \\
\text { group }\end{array}$ \\
\hline \multicolumn{3}{|l|}{$>35$ wk gestation } \\
\hline No. of patients & 36 & 19 \\
\hline Gestational age at birth (wk) & $38.7 \pm 1.7$ & $37.8 \pm 1.6$ \\
\hline Birth wt $(\mathrm{g})$ & $3253 \pm 659$ & $3061 \pm 458$ \\
\hline $\begin{array}{l}\text { Age at spontaneous closure of } \\
\text { ductus arteriosus (h) }\end{array}$ & $35.1 \pm 24.6$ & $31.3 \pm 15.3$ \\
\hline \multicolumn{3}{|l|}{$\leq 35$ wk gestation } \\
\hline No. of patients & 17 & $22 \dagger$ \\
\hline Gestational age at birth (wk) & $30.4 \pm 3.4$ & $31.1 \pm 3.0$ \\
\hline Birth wt (g) & $1568 \pm 669$ & $1708 \pm 582$ \\
\hline $\operatorname{RDS}(n, \%)$ & $7(41)$ & $6(27)$ \\
\hline \multicolumn{3}{|l|}{ Spontaneous closure of ductus } \\
\hline$n(\%)$ & $10(59)$ & $16(73)$ \\
\hline Age at closure $(\mathrm{h})$ & $36.7 \pm 28.7$ & $21.0 \pm 7.5$ \\
\hline \multicolumn{3}{|l|}{ Infants treated with indomethacin } \\
\hline$n(\%)$ & $4(24)$ & $5(23)$ \\
\hline \multicolumn{3}{|l|}{ Age at first dose } \\
\hline$<3 \mathrm{~d}(n)$ & 2 & 2 \\
\hline$>3 \mathrm{~d}(n)$ & 2 & 3 \\
\hline Two doses needed $(n)$ & 1 & 1 \\
\hline $\begin{array}{l}\text { Interval between first dose and } \\
\text { closure of PDA (h) }\end{array}$ & $69 \pm 46$ & $60 \pm 34$ \\
\hline Infants treated with ligation $(n, \%)$ & $3(17)$ & $0(0)$ \\
\hline Ductal reopening $(n, \%)$ & $3(17)$ & $0(0)$ \\
\hline
\end{tabular}

* All values are mean \pm SD or mean and percentage.

$\dagger$ One infant died at the age of $26 \mathrm{~h}$ of RDS. Indomethacin was not given, and autopsy revealed open ductus.

Altogether, 39 infants were born at or before $35 \mathrm{wk}$ of gestation ( 17 in the indomethacin group and 22 in the nylidrin group). No detectable difference in gestational age $(p=0.27)$, birth weight $(p=0.31)$, or incidence of $\operatorname{RDS}(p=0.36)$ was encountered. The incidence of spontaneous closure of ductus $(p=0.36)$ and the age of closure $(p=0.14)$ were not significantly different between the groups. Among the infants delivered within $3 \mathrm{~d}$ after discontinuation of maternal treatment, there were two cases (one in both groups) with spontaneous closure of ductus before $6 \mathrm{~h}$ of age $(p>0.5)$.

Nine infants required indomethacin for closure of ductus postnatally (four in the indomethacin group and five in the nylidrin group; $p=0.69$ ). The first dose of indomethacin was given to both groups of infants at similar ages $(p=0.53)$, and the PDA closed at similar intervals after the first dose in both groups $(p=0.75)$. Two neonates received two courses of indomethacin (one in both groups).

Surgical ligation of PDA was performed in three infants who received indomethacin for treatment of preterm labor. In these neonates, the mean gestational age was $26.0 \mathrm{wk}$ (range, 24.7 to $27.9 \mathrm{wk}$ ), and the mean birth weight was $790 \mathrm{~g}$ (range, 630 to $1020 \mathrm{~g}$ ). The ligations were performed at 7, 20, and $44 \mathrm{~d}$ of age. None of the infants in the nylidrin group were ligated $(p=0.15)$.

Ductal reopening was detected in three infants (gestational age, 24.7, 25.4, and $30.0 \mathrm{wk}$ ). They all were born less than $3 \mathrm{~d}$ after discontinuation of maternal indomethacin treatment. In these infants, ductus was initially closed within $4 \mathrm{~d}$ after birth (two spontaneous closures and one after indomethacin treatment). Ductal reopening was evident at 16,20, and $40 \mathrm{~d}$ of age. Ductus was closed with indomethacin in one infant, and two infants required ligation. None of the infants in the nylidrin group had ductal reopening ( $p=0.15$ ).

Pulmonary hypertension in neonates. Three premature neonates had persistent pulmonary hypertension (two in the indomethacin and one in the nylidrin group; $p=0.7$ ). In the indomethacin group, two twins (27.0 wk of gestation) had severe
RDS accompanied by pulmonary hypertension. One twin survived; the other died at the age of $18 \mathrm{~h}$. One infant $(34.0 \mathrm{wk}$ gestation) who was born during nylidrin treatment survived after intensive treatment of RDS and pulmonary hypertension.

\section{DISCUSSION}

The fetal ductal constriction is characterized by increased systolic and diastolic ductal flow velocities, resulting in a Doppler wave form similar to that seen postnatally across coarctation of the aorta (11). In a previous study (7), ductal constriction occurred in seven of the 14 fetuses studied. In the present study, the incidence of ductal constriction was $86 \%$ in indomethacintreated fetuses and $78 \%$ in studies performed during indomethacin treatment. Indomethacin crosses the human placenta easily throughout gestation (6). The ductal constriction occurred as early as $24.0 \mathrm{wk}$ and as late as $34.0 \mathrm{wk}$. In addition, PDV in the ductus was clearly elevated $(38 \mathrm{~cm} / \mathrm{s})$ in a fetus with very early gestational age (22.9 wk), indicating that the ductus was reactive to indomethacin. The mean gestational age of the fetuses with ductal constriction was higher than that of those without constriction. In addition, there was a significant linear positive relationship between the gestational age and PSV or PDV in the ductus arteriosus during indomethacin treatment. These results confirm our earlier findings (9) that the ductus becomes more reactive to indomethacin with increasing gestational age.

A modest increase in PSV in the ductus was evident in fetuses exposed to nylidrin. PDV in the ductus was not increased. Elevated PSV is likely due to an increased flow volume in the right heart (14). An increased flow through a wide-open ductus shows a Doppler pattern with a rapid decrease after PSV to the baseline and, once again, an increase in diastole and a decrease toward end-diastole. In ductal constriction, flow velocity across the ductus arteriosus slowly decreases from its maximum to enddiastole. Therefore, during nylidrin treatment, the shape of the Doppler wave form is different from that seen during ductal constriction (14). In this study, a moderate increase in PSV in the ductus with advancing gestational age is in agreement with previous studies (15).

In animal studies, acute fetal ductal occlusion imposes a marked increase in the right ventricular afterload, resulting in reversible TR (16). In this study, TR occurred in 11 of 49 fetuses treated with indomethacin $(22 \%)$ and in 11 of 42 fetuses with ductal constriction (26\%). TR developed as early as $25.7 \mathrm{wk}$ gestation and as late as $34.0 \mathrm{wk}$ gestation. The mean gestational age of the fetuses with TR tended to be greater than that of those without TR. In addition, the constrictive response of the ductus increased with gestational age. According to these findings, an intensive constriction of the ductus causes pressure and afterload increase in the right ventricle, resulting in TR. In fetuses with very early gestational age, the myocardium and the papillary muscles may not tolerate even a slight pressure increase in the right ventricle caused by ductal constriction.

There are reports of pulmonary hypertension in newborn infants after administration of indomethacin $(17,18)$. In the present study, no significant difference in the incidence of pulmonary hypertension between the groups could be found; in three premature infants (two in the indomethacin group and one in the nylidrin group), pulmonary hypertension was associated with severe RDS.

A decreased incidence of PDA after prenatal exposure to indomethacin in preterm babies has been demonstrated (19). In the present study, however, the frequencies of both spontaneous closure of PDA and of the requirement of indomethacin for treatment of PDA were similar in both study groups. Ligation of PDA was performed in three infants who were exposed to indomethacin before birth; two of them had ductal reopening. Ductal reopening was found in three of 17 infants (17\%): two after primary spontaneous closure and one after successful indomethacin-induced closure. None of the infants in the nylidrin 
group had ductal reopening. According to these and other findings (20), the ductus in immature babies maintains its ability to contract and relax after indomethacin treatment.

In conclusion, although indomethacin may have a therapeutic role in specific pregnancies, it has serious hemodynamic side effects that are related to fetal ductal constriction. In view of this study, measurement of ductal flow velocities and evaluation of tricuspid valve function are necessary when indomethacin is administered prenatally especially with increasing gestational age. In premature infants, prenatal administration of indomethacin did not decrease the need for PDA treatment.

Acknowledgments. The author thanks Dr. Mikko Hallman, Dr. Erkki Pesonen, Dr. Tapio Kurki, and Dr. Olavi Ylikorkala for their assistance in various aspects of this work.

\section{REFERENCES}

1. King JF, Grant A, Kreise MJ, Chalmers I 1988 Betamimetics in preterm labor: an overview of randomized controlled trials. Br J Obstet Gynaecol 95: $211-222$

2. The Canadian Preterm Labor Investigation Group 1992 Treatment of preterm labor with the beta-adrenergic agonist ritodrine. N Engl J Med 327:308-312

3. Martin AJ 1981 Severe unwanted effects associated with betasympathomimetics when used in the treatment of premature labor: causes, incidence and preventative measures. Br J Clin Pract 35:325-329

4. Katz VL, Seeds HW 1989 Fetal and neonatal cardiovascular complications from $\beta$-sympathomimetic therapy for tocolysis. Am J Obstet Gynecol 161: $1-4$

5. Gemelli M, Luca FD, Manganaro R, Leonardi R, Rando F, Agnetti A, Mami C, Di Paquale G 1990 Transient electrocardiographic changes suggesting myocardial ischaemia in newborn infants following tocolysis with betasympathomimetics. Eur J Pediatr 149:730-733

6. Moise KJ, Ou C-N, Kirshon B, Cano LE, Rognerud C, Carpenter RJ 1990 Placental transfer of indomethacin in the human pregnancy. Am $\mathrm{J}$ Obstet Gynecol 162:549-554

7. Moise KJ, Huhta JC, Sharif DS, Ou C-N, Kirshon B, Wasserstrum N, Cano L 1988 Indomethacin in the treatment of premature labor. Effects on the fetal ductus arteriosus. N Engl J Med 319:327-331
8. Gersony WM, Peckham GJ, Ellison RC, Miettinen OS, Nadas AS 1983 Effects of indomethacin in premature infants with patent ductus arteriosus: results of a national collaborative study. J Pediatr 102:895-906

9. Eronen M, Pesonen E, Kurki T, Ylikorkala O, Hallman M 1991 The effects of indomethacin and a $\beta$-sympathomimetic agent on the fetal ductus arteriosus during treatment of premature labor: a randomized double-blind study. Am J Obstet Gynecol 164:141-146

10. Kurki T Eronen M, Lumme R, Ylikorkala O 1991 A randomized doubledummy comparison between indomethacin and nylidrin in threatened preterm labor. Obstet Gynecol 78:1093-1097

11. Huhta JC, Moise KJ, Fisher DJ, Sharif DS, Wasserstrum N, Martin C 1987 Detection and quantitation of constriction of the fetal ductus arteriosus by Doppler echocardiography. Circulation 75:406-412

12. Mellander M, Sabel K-G, Mellgren G 1986 Single Doppler detection of the left to right shunt through the ductus arteriosus. Acta Paediatr Scand [Suppl] 329:98-102

13. Musewe NN, Poppe D, Smallhorn JF, Hellman J, Whyte H, Smith B, Freedom RM 1990 Doppler echocardiographic measurements of pulmonary artery pressure from ductal Doppler velocities in the newborn. J Am Coll Cardiol 15:446-456

14. Tulzer G, Gudmundsson S, Sharkey AM, Wood DC, Cohen AW, Huhta JC 1991 Doppler echocardiography of fetal ductus arteriosus constriction versus increased right ventricular output. J Am Coll Cardiol 18:532-536

15. van der Mooren K, Barendregt LG, Wladimiroff JW 1991 Flow velocity wave forms in the human fetal ductus arteriosus during the normal second half of pregnancy. Pediatr Res 30:487-490

16. Tulzer G, Gudmundsson S, Rotondo KM, Wood DC, Yoon GY, Huhta JC 1991 Acute fetal ductal occlusion in lambs. Am J Obstet Gynecol 165: $775-778$

17. Levin DL, Mills LJ, Weinberg AG 1979 Hemodynamic, pulmonary vascular, and myocardial abnormalities secondary to pharmacologic constriction of the fetal ductus arteriosus. Circulation 60:360-364

18. Manchester D, Mayolis HS, Sheldon RE 1976 Possible association between maternal indomethacin therapy and primary pulmonary hypertension of the newborn. Am J Obstet Gynecol 126:467-469

19. Baerts W, Fetter WPF, Hop WCJ, Spritzer R, Sauer PJJ 1990 Cerebral lesions in preterm infants after tocolytic indomethacin. Dev Med Child Neurol 32:910-918

20. Clyman RI, Campbell D, Heymann MA, Mauray F 1985 Persistent responsiveness of the neonatal ductus arteriosus in immature lambs: a possible cause for reopening of patent ductus arteriosus after indomethacin-induced closure. Circulation 71:141-145 